\title{
Screening of Local and Introduced Varieties of Pogostemon heyneanus Benth. (Lamiaceae), for Superior Quality Physical, Chemical and Biological Parameters
}

\author{
R.M. Dharmadasa ${ }^{1, *}$, R.M.D.H. Rathnayake ${ }^{2}$, D.C. Abeysinghe ${ }^{2}$, S. A. N. Rashani ${ }^{1}$, K. Samarasinghe ${ }^{1}$, \\ A.L.M Attanayake ${ }^{1}$ \\ ${ }^{1}$ Herbal Technology Section, Industrial Technology Institute, Bauddhaloka Mawatha, Colombo 7, Sri Lanka \\ ${ }^{2}$ Department of Plantation Management, Faculty of Agriculture and Plantation Management, Wayamba University of Sri Lanka, \\ Makandura, Gonawila (NWP), Sri Lanka \\ *Corresponding author: dharmadasarm@gmail.com, dharma@iti.lk
}

Received October 29, 2014; Revised November 06, 2014; Accepted November 09, 2014

\begin{abstract}
Pogostemon heyneanus Benth. (Lamiaceae) is an aromatic, perfumery important, industrial crop widely cultivated in many Asian countries for its distinguished fragrance and other therapeutic purposes. However, commercial cultivation of $P$. heyneanus was hampered due to lack of high quality planting materials. Purpose of the present study is to explore superior quality $P$. heyneanus variety by means of physical (morphological), chemical (physico-chemical, phytochemical, essential oil content and composition) and biological [total antioxidant capacity (TAC)] parameters in order to establish commercial cultivation. Morphological, physico-chemical and phytochemical analysis were performed according to the methods described in WHO guidelines and other classical texts. The TAC was performed using Ferric Reducing Antioxidant Power (FRAP) assay. Essential oil was analyzed by gas chromatography Mass Spectrometry (GC/MS). Out of 26 morphological characters assessed, 5 characters were i.e. plant height, leaf margin, leaf apex, and leaf base and leaf shape polymorphic. All phytochemicals tested were identical to both varieties. However, presence of a prominent spots at Rf 0.12 (dark brown spot), 0.20 (rose colour spot), 0.45 (dark green spot) were characteristic for local variety. Significantly higher total ash content (12.32 \%), oil content (0.52\%), higher number of compounds in essential oil, patchouli alcohol content (57.0\%) and antioxidant capacity (108.53 $\pm 2.5 \mathrm{mg}$ Trolox equivalent per g of extract) were reported in introduced variety. According to the results, introduced variety possesses superior quality physical, chemical and biological properties and therefore, introduced variety could be recommended for establishment of commercial cultivation.
\end{abstract}

Keywords: Pogostemon heyneanus, Lamiaceae, antioxidant capacity, GC MS analysis, essential oil, Patchouli alcohol

Cite This Article: R.M. Dharmadasa, R.M.D.H. Rathnayake, D.C. Abeysinghe, S. A. N. Rashani, K. Samarasinghe, and A.L.M Attanayake, "Screening of Local and Introduced Varieties of Pogostemon heyneanus Benth. (Lamiaceae), for Superior Quality Physical, Chemical and Biological Parameters." World Journal of Agricultural Research, vol. 2, no. 6 (2014): 261-266. doi: 10.12691/wjar-2-6-2.

\section{Introduction}

Pogostemon heyneanus Benth (Lamiaceae) is a fragrant, industrially important medicinal and aromatic herb found in Western to Southern in India, Malay Peninsula, Philippine Islands and Sri Lanka. It is known as Gankollankola or Kollankola in Sinhala Patraka, Sughandaka in Sanskrit and Pachouli or Java patchouli in English [1]. Patchouli oil is a product distilled from areal parts of Pogostemon species such as Pogostemon cablin, Pogostemon heyneanus, Pogostemon speciosus or other Pogostemon species grown in different geographic regions in the world. Patchouli oil is distinguished for its deep, earthy and musky fragrance and hence it is mainly used in perfumery industry [2,3]. In addition, patchouli oil is a major component of soaps, cosmetics, fragranced products like paper towels, laundry detergents, and air fresheners. Composition of essential oil (patchouli oil) also varied according to the species. The essential oil obtained from Pogostemon speciosus contained $\alpha$-bisabolol (40.8\%), caryophyllene (4.5\%), cubebol (5.3\%) and [4] while Pogostemon cablin contained Patchoulol (40-70\%). $\alpha-$ pinene and $\beta$-pinene contained as major constituents of $P$. heyneanus [5]. These major phytochemicals and different constituents are responsible for an array of therapeutic properties such as anti-fungal and bacteriostatic properties [6], protection against influenza viral infection [7], antitumorigenic activity [8] and anti-inflammatory activity [8,9]. Further, Patchouli oil has been used as insect repellent materials. Although $P$. heyneanus possesses a diverse range of therapeutic effects, industrial potential and traditional uses, commercial cultivation in Sri Lanka is hampered due to unavailability of economically viable superior quality planting materials in order to establish 
commercial cultivation. Therefore, selection of economically viable superior quality planting materials with desired physical chemical and biological properties is yet to be investigated in order to establish commercial scale cultivation. In the present study we attempted to select superior quality variety of $P$. heyneanus by means of higher oil content, patchouli alcohol content and higher antioxidant capacity in order to generate planting materials for establishment of commercial cultivation in Sri Lanka.

\section{Materials and Methods}

\subsection{Plant Materials}

Plants for morphological studies were obtained from six months old $P$. heyneanus mother plants maintained under same soil and climatic conditions. Herbaria for all both varieties were prepared (HTS 50 and HTS 51) and authenticated by comparing with herbarium specimens deposited at National Herbarium at Royal Botanical Garden. Plant materials for phytochemical, physicochemical, essential oil distillation and antioxidant assay were obtained from the above maintained plants.

\subsection{Morphological Studies}

Same aged twenty five plants of each variety which were maintained at same soil and climatic conditions were used for morphological study. Taxonomically significant vegetative characters of both varieties were recorded and tabulated.

\subsection{Preparation of Samples for Analysis}

Fully matured leaves were harvested from six months old plants and cut into pieces. Then the samples were dried at room temperature $\left(28 \pm 2^{\circ} \mathrm{C}\right)$ for 5 days. The dried leaves were powdered using an electric grinder (Junke and Staufen, Germany) and used for physicochemical, phytochemical, antioxidant and essential oil extraction.

\subsection{Phytochemical, Physicochemical and Antioxidant Activity}

\subsubsection{Extraction of Plant Materials}

Ten grams of powdered plant material of each variety was extracted with $50 \mathrm{~mL}$ of methanol by using Soxhlet apparatus. The extract was concentrated at $45^{\circ} \mathrm{C}$ using rotovapour (Buchi Rotavapour, Type-R-114A29 B-480, and Switzerland).

\subsubsection{Phytochemical Screening}

The preliminary phytochemical screening tests were carried out for flavonoids, alkaloids, steroid glycosides saponins, and tannins according to the method described by Farnsworth [30].

\subsubsection{Quantification of Total Ash}

Two grams of air dried materials ignited at $500-600^{\circ} \mathrm{C}$ until the sample turn into white colour. Then the total ash content of ignited sample was determined as methods described in WHO guidelines [10].

\subsubsection{Quantification of Water-Soluble Ash}

Previously ignited ash sample was mixed with $25 \mathrm{~mL}$ of distilled water and boiled with $25 \mathrm{~mL}$ Then it was filtered using a Whatman ashless filter-paper. Insoluble matter was washed with hot water and ignited for $15 \mathrm{~min}$ at $450^{\circ} \mathrm{C}$. The residue was allowed to cool in a desiccator for 30 minutes [10].

\subsubsection{Quantification of Acid-Insoluble Ash}

Pre ignite crucible containing ash was gently boiled with $25 \mathrm{~mL}$ of $\mathrm{HCl}$. Insoluble matter was collected to Whatman ashless filter-paper and washed with hot water until the filtrate become neutral. Then the acid insoluble matter was transferred to original crucible and ignited to a constant weight at $450^{\circ} \mathrm{C}$. Then the residue was allowed to cool in a desiccator for 30 minutes [10].

\subsubsection{Quantification of Total Extractable Matter}

Hot extraction method - Coarsely powdered samples (4g each) of leaf, stem and flower were separately refluxed with $100 \mathrm{~mL}$ of methanol for $1 \mathrm{~h}$. Then the mixture was filtered and total weight was re-adjusted by adding methanol. Then $25 \mathrm{~mL}$ of the filtrate was concentrated in a rotavapour (Buchi Rotavapour, Type-R114A29 B-480, Switzerland) at $45^{\circ} \mathrm{C}$. The residue was dried at $105^{\circ} \mathrm{C}$ for $6 \mathrm{~h}$ and allowed to cool for $30 \mathrm{~min}$. The weight was recorded [10].

\subsubsection{Cold Maceration Method}

Four grams of coarsely powdered, sample was macerated with $100 \mathrm{~mL}$ of methanol for $6 \mathrm{~h}$. Then it was allowed to stand for $18 \mathrm{~h}$ and filtered. Then $25 \mathrm{~mL}$ of the filtrate was concentrated in a rotary evaporator at $45^{\circ} \mathrm{C}$. The residue was dried at $105^{\circ} \mathrm{C}$ for $6 \mathrm{~h}$, cooled in a desiccator for 30 minutes.

\subsubsection{Quantification of Total Phenolics}

The total phenolic content was determined by using modified Folin-Ciocaltue method (Abeysinghe et al). Briefly, $4 \mathrm{~mL}$ of distilled water and $0.5 \mathrm{~mL}$ of plant extract were mixed in a test tube. Then $0.5 \mathrm{~N}$ Folin Ciocalteu reagents $(0.5 \mathrm{~mL})$ was added and allowed to react for $3 \mathrm{~min}$. saturated sodium carbonate solution $(1 \mathrm{~mL})$ was mixed and samples were incubated in a water bath for $2 \mathrm{~h}$ at $30^{\circ} \mathrm{C}$. The absorbance was measured at $760 \mathrm{~nm}$ using UV visible spectrophotometer (Shimadzu UV-160). Gallic acid was used as the standard and TPC in one gram of dried plant material was calculated and expressed as milligram of Gallic Acid Equivalent (GAE).

\subsubsection{Determination of Total Antioxidant Capacity (TAC)}

Total antioxidant capacity was determined using Ferric Reducing Antioxidant Power (FRAP) assay as described by Benzie and Strain [12]. Methanolic extract $(100 \mu \mathrm{L})$ was mixed with $900 \mu \mathrm{L}$ of freshly prepared FRAP reagent of $\mathrm{pH} 3.6$ containing $2.5 \mathrm{~mL}$ of $10 \mathrm{mmol} / \mathrm{L}, 2,4,6-$ Tripyridyl-s-Triazine (TPTZ), $2.5 \mathrm{~mL}$ of $20 \mathrm{mmol} / \mathrm{L} \mathrm{FeCl}_{3}$ and $25 \mathrm{~mL}$ of $300 \mathrm{mmol} / \mathrm{L}$ acetate buffer. Absorbance of the reaction was measured at $593 \mathrm{~nm}$ using the spectro photometer (Shimadzu, UV Mini 1240, Japan) after incubating for $4 \mathrm{~min}$. Trolox was used as the standard and 
TAC in one gram of dried plant material was calculated and expressed as mg of Trolox Equivalent (TE).

\subsubsection{Distillation of Essential Oil}

Well-dried leaf samples of each variety of $P$. heyneanus separately hydro-distilled in a Clevenger-type distillation apparatus for $8 \mathrm{~h}$. The oil was collected and dried over anhydrous sodium sulfate and stored under refrigeration until analysis. The yield of the oils was calculated based on dry weight of plant materials.

\subsubsection{Gas Chromatography-Mass Spectrometry (GC- MS) Analysis}

GC-MS analysis was carried out on a Hewlett-Packard 6890 Gas Chromatograph fitted with a fused silica HP5 MS capillary column $(30 \mathrm{~m} \times 0.25 \mathrm{~mm}$; film thickness $0.25 \mu \mathrm{m})$. The oven temperature was programmed from 60 - $280^{\circ} \mathrm{C}$ at $4^{\circ} \mathrm{C} / \mathrm{min}$. Helium was used as carrier gas at a flow rate of $2 \mathrm{~mL} / \mathrm{min}$. The gas chromatograph was coupled to a Hewlett-Packard 6890 mass selective detector. The MS operating parameters were ionization voltage, $70 \mathrm{eV}$; and ion source temperature, $200^{\circ} \mathrm{C}$. The constituents of essential oil were identified by means of their GC retention indices (RI) and also by comparing the fragmentation pattern in the mass spectra of the peaks with those reported in the literature and NIST and Wiley MS library databases.

\subsubsection{Statistical Analysis}

Results of morphological characters were averaged of 20 plants. Data on physico-chemical parameters and antioxidant activity were analyzed by General Linear Model (GLM) ANOVA test followed by Duncan's Multiple Range Test (DMRT). Statistical comparison of mean values was performed by General Liner Model (GLM) of ANOVA followed by Turkey Multiple Range Test using Minitab 15 version and presented means \pm SD.

\section{Results and Discussion}

Present work compared the morphological, phytochemical (alkaloids, flavonoids, saponins, steroid glycosides and tannins \& TLC fingerprints), physico-chemical (moisture, total ash, water soluble ash, acid insoluble ash and extractable matter contents) total phenol content (TPC), total antioxidant capacity (TAC), essential oil content and essential oil composition of two varieties of $P$. heyneanus which is industrially potential fragrance plants grown in Sri Lanka.

As shown in Table 1, the most of the characters are monomorphic in both local and introduced varieties. This is quite acceptable as both varieties belonging to same family, genus and species. In spite of huge morphological resemblance these two verities can be authenticated by their prominent polymorphic morphological characters such as plant height, leaf margin, leaf apex, leaf base and leaf texture as well as leaf area (Table 1). Moreover, presence of comparatively larger leaves and higher leaf area value in introduced variety, directly influence on biomass of the plant and finally increase the yield of the crop. The most of the characters we have observed in both varieties are in agreement with previous studies $[1,4]$ which reported the extensive morphological description of Pogostemon species.

Plant secondary metabolites play an important role on therapeutic effect of a given plant. Therefore, investigation of phytochemical, physicochemical, antioxidant capacity, essential oil content and composition are vital important in standardization and quality control of medicinal materials $[13,14]$. As shown in Table 2, current study demonstrated the presence of alkaloids, flavanoids, saponins, and tannins in both varieties of $P$. heyneanus. Conversely, steroid glycosides are absent in both varieties. According to the results, it seems that preliminary phytochemicals present in both varieties are similar.

Table 1. Prominent morphological features of local and introduced varieties of Pogostemon heyneanus

\begin{tabular}{lll} 
varieties of Pogostemon heyneanus & Local variety & Introduced variety \\
\hline Plant habit & Much branched & Much branched \\
Plant height (cm) & $90-110 \mathrm{~cm}$ & $140 \mathrm{~cm}-150 \mathrm{~cm}$ \\
Leaf type & Simple & Simple \\
Leaf length (cm) & $9.5-12.2 \mathrm{~cm}$ & $11 \mathrm{~cm}-12 \mathrm{~cm}$ \\
Leaf width (cm) & $7.2-9.0 \mathrm{~cm}$ & $9 \mathrm{~cm}-10 \mathrm{~cm}$ \\
Length: width ratio & 1.5 & 1.2 \\
Leaf margin & Double serrate & Serrate \\
Leaf apex & Acuminate & Acute \\
Leaf shape & Ovate & Triangular \\
Leaf base & Acute & Truncate \\
Leaf arrangement & Opposite & Opposite \\
Leaf surface colour (upper) & Green & Green \\
Leaf surface colour (lower) & Light green & Purplish green \\
Leaf texture & Smooth & Rough \\
Leaf area & $40 \mathrm{~cm}{ }^{2}-50 \mathrm{~cm}{ }^{2}$ & $65 \mathrm{~cm}{ }^{2}-70 \mathrm{~cm}{ }^{2}$ \\
No. of veins per leaf & $6-10$ & $11-12$ \\
Venation & Pinnate & Pinnate \\
Leaf trichome (present/ absent) & Present & Present \\
Petiole length (cm) & $3.5-5.8 \mathrm{~cm}$ & $3.5 \mathrm{~cm}-4.0 \mathrm{~cm}$ \\
Petiole colour & Light green & Green \\
Petiole grove (present/absent) & Present & Absent \\
Stem colour & Pale green & Purplish green \\
Intermodal space (cm) & $5.75-6.5 \mathrm{~cm}$ & $3.93-4.20 \mathrm{~cm}$ \\
Stem shape & Quadrangular & Quadrangular \\
Stem trichome & Present & Present \\
\hline
\end{tabular}

Results of the physicochemical parameters of two varieties of $P$. heyneanus are presented in Table 3 . Moisture content of local and introduced varieties was $11.95 \pm 0.03$ and $10.08 \pm 0.50$ respectively. Extractable matter content is one of the most important parameters used for the characterization of botanical drugs [15]. Significantly higher total ash content (12.32 \pm 0.68$)$ and extractable matter content $(14.48 \pm 0.06)$ was observed in local variety. Since the ash represents the physiological (derived from plant itself such as calcium oxalate and silicate) and non-physiological (accumulated from external environment such as sand, soil, adulterants etc.) impurities, determination of these parameters are vital important in order to maintain the purity of the herbal medicine [15,16,17]. Moreover, acid insoluble ash and water soluble ash content of both varieties were similar. Determination of ash values are vital important in order to maintain the purity of the herbal medicine. Present study reveals the total ash and water soluble ash contents were not significantly $(\mathrm{p}<0.05)$ different in both varieties. Information on physico-chemical and phytochemical parameters generated through the present study could be 
incorporated in standardization of quality, purity and sample identification of both varieties of $P$. heyneanus.

Table 2. Comparative phyotochemical analysis of two Pogostemon heyneanus varieties grown in Sri Lanka

\begin{tabular}{lll} 
Metabolite & \multicolumn{2}{l}{} \\
\cline { 2 - 3 } 1. Saponins & Local variety & Introduced variety \\
\cline { 2 - 3 } 2. Alkaloids & + & + \\
3. Tanins & + & + \\
4. Flavanoids & + & + \\
5. Steroid Glycosides & - & + \\
\hline$(+)=$ Presence $(-)=$ Absence & - \\
\hline
\end{tabular}

Table 3. Physico-chemical parameters of different variety of Pogostemon heyneanus Benth

\begin{tabular}{lll}
\hline Parameter & Plant Variety & \\
\hline & Introduced variety & Local Variety \\
Total ash & $10.61 \pm 0.05^{\mathrm{b}}$ & $12.32 \pm 0.68^{\mathrm{c}}$ \\
Water soluble ash & $5.41 \pm 0.39^{\mathrm{b}}$ & $6.24 \pm 0.09^{\mathrm{b}}$ \\
Acid insoluble ash & $0.78 \pm 0.43^{\mathrm{a}}$ & $0.38 \pm 0.08^{\mathrm{a}}$ \\
Moisture content & $11.95 \pm 0.03^{\mathrm{b}}$ & $10.08 \pm 0.51^{\mathrm{c}}$ \\
Extractable matter & & \\
Hot Extraction & $11.54 \pm 0.06^{\mathrm{b}}$ & $14.48 \pm 0.06^{\mathrm{c}}$ \\
Cold Extraction & $12.42 \pm 0.09^{\mathrm{a}}$ & $11.59 \pm 0.42^{\mathrm{a}}$ \\
\hline
\end{tabular}

Results are the means of three replicates; \pm SD, Means followed by same letter are not significantly different at 0.05 levels.

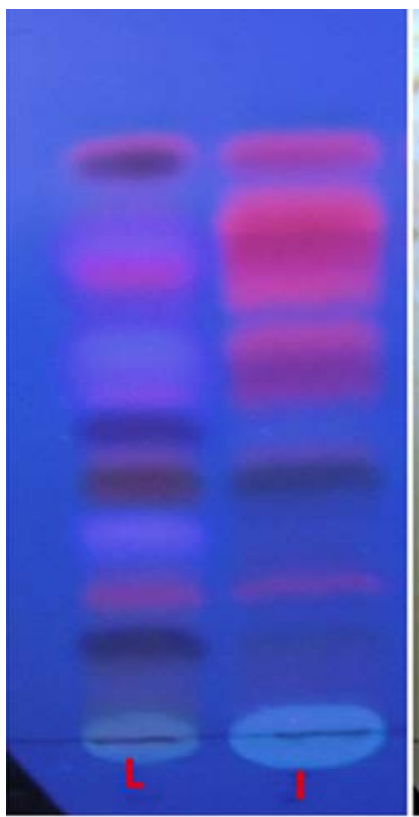

A

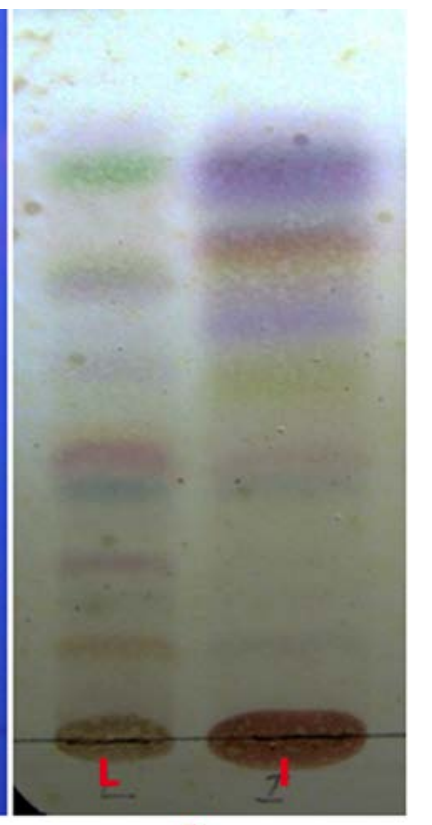

B
Figure 1. (A) Thin layer chromatographic profiles of two varieties of Pogostemon heyneanus Benth. under UV 366 nm; B. Thin layer chromatography of two varieties of Pogostemon heyneanus Benth. after spraying vanillin sulfate (L)-local variety, (I) - introduced variety [Solvent system chloroform: cyclohexane dicloromethane: methanol $(1: 1: 2: 0.2)]$

Thin Layer Chromatography is a widely used technique for screening of herbal materials and herbal products and to differentiate between herbal species due to its simplicity, cost effectiveness, less time consuming and the ability of changing the solvent system [18,19]. Further, use of TLC fingerprint pattern for determining the identity, stability, and consistency of traditional medicine and identification of adulterants included to Panax species have been investigated [20,21]. In the present study we have observed TLC finger prints of leaf extracts of two varieties of $P$. heyneanus under UV 366 and after spraying with Vanillin sulfuric acid. TLC profile observed under UV $366 \mathrm{~nm}$ of local variety exhibited 11 spots while introduced variety showed only 9 spots. Out of these, seven spots were common for both varieties. Presence of similar spots of both varieties is obvious because both are belong to same genus and species. Nevertheless, spots appeared on Rf 0.12 (dark brown spot), 0.20 (rose colour spot), 0.45 (dark green spot) are specific to local variety (Figure 1). When consider the TLC profile sprayed with vanillin sulfuric acid also exhibited higher number of spots from local variety. These varietal specific spots could be used for authentication of these two varieties. Thin layer chromatographic profile have been successfully used for authentication of Acmella oleraceae [22], Munronia pinnata and Andrographis paniculata [23], for authentication of field grown and hydroponically grown Acmella oleracea [24] and Gyrinops walla [25].

Table 4. Percentage composition and comparison of oil profiles of two varieties of Pogostemon heyneanus

Peak No. Compound Compound \%

13.7

14.98

$\alpha$-pinene Introduced variety Local variety

16.88

$\beta$ - pinene

14.25

17.62

Limonene

30.99

26.90

Ethanone

2.38

1,3-butanedione

16.87

26.94

$\beta$-Pachoulin

1.71

28.01

Seychellene

4.19

28.38

$\beta$ - caryophyllene

14.79

28.71

$\alpha$-guaiene

2.15

2.20

29.36

Guaia

-

2.38

31.21

Nerolidol

14.79

33.39

Patchouli alcohol

57.12

15.49

7.14

Essential oil content of local variety was lower (0.4\%) than the introduced variety (2.4\%). Results on oil compositions of local and introduced varieties are shown in Table 4. A total of five constituents from introduced variety and nine constituents from local variety which represent over $90 \%$ of the oil constituents were identified according to mass spectrum of each constituent.

Out of identified constituents, $\beta$ - caryophyllene and patchouli alcohol were shared constituents of both species. Patchouli alcohol (57.12\%), Guaia (14.79\%) and Seychellene (14.79\%) were identified as major constituents of essential oil of introduced variety, while $\beta$ - pinene (30.99\%), ethanone $(16.87 \%)$ and nerolidol $(15.49 \%)$ were major constituents of local variety. In the commercial point of view, cultivation of patchouli with higher content of Patchouli alcohol exists higher demand in the global market. Therefore, it could be suggested to commence commercial cultivation with introduced variety of Pogostemon heyneanus by means of Patchouli alcohol.

Results of the current study are in agreement with Sundaresan et al., who investigated the compositional analysis of essential oil of 2 species of Pogostemon [26] Moreover, compounds identified in the present study are major compounds found in patchouli oil $[26,27,28]$. 
Table 5. Total Antioxidant Capacity (TAC) and Total Phenolic Content (TPC) of local and introduced varieties cultivated in Hydroponic system and field planted

\begin{tabular}{lll}
\hline Variety & $\begin{array}{l}\text { TAC (mg Trolox } \\
\text { per g of extract) }\end{array}$ & $\begin{array}{l}\text { TPC (mg Gallic acid } \\
\text { Equelent per g of sample) }\end{array}$ \\
\hline Local variety & $6.88 \pm 0.26$ & $0.83 \pm 0.01$ \\
Introduced variety & $108.53 \pm 2.5$ & $6.41 \pm 1.10$ \\
\hline
\end{tabular}

Polyphenols are group of secondary metabolites which is responsible for an array of physiological properties [29]. Total polyphenolic content and antioxidant capacity play a significant role on therapeutic value of the medicinal plants. Antioxidants and phenols are mainly responsible for the defense mechanisms of a plant [30]. In the present study, TPC and TAC of leaf extracts of two varieties of $P$. heyneanus were compared. Results clearly demonstrated the presence of significantly higher TPC (6.41 mg Gallic acid Equelent per g of sample) and antioxidant capacity (108.53 mg Trolox per g of extract) in leaf extract of introduced variety. Results of the present study are in agreement with Abdullah Hussain et al. [31], who reported the higher antioxidant capacity in essential oil of Pogostemon species.

Results of morphological, phytochemical, essential oil content and composition, total phenolic content and antioxidant capacity clearly demonstrated the superior herbage yield, high oil content, higher patchouli alcohol content, higher antioxidant and phenolic content in introduced variety over the local variety. Therefore, in the commercial point of view establishment of commercial scale cultivations using introduced variety could expect higher commercial value.

\section{Conclusion}

Present study clearly demonstrates high oil content, antioxidant capacity and Total phenolic content and higher content of patchouli alcohol in introduced variety in the first time in Sri Lanka. Therefore, introduction of commercial scale cultivation of $P$. heyneanus by using introduced variety could be suggested. Information generated through the present study could be incorporated for quality control and standardization of $P$. heyneanus and upgrade the Sri Lankan pharmacopeia.

\section{Acknowledgements}

Authors wish to acknowledge all staff members of the institute for their kind support.

\section{References}

[1] Jayaweera, D.M.A., 1981. Medicinal Plants (Indigenous and Exotic) Used in Ceylon, 3 pp 110-111.

[2] Robbins, S.R.J., 1983. Natural essential oils. Current trends in production, marketing and demand. Perfumer and Flavorist. 8, 7582.

[3] Tao, C., 1983. China's burgeoning aromatic industry. Perfumer and Flavorist. 7, 1. Ting Qiu and Haixing Liand Yusheng Cao., 2010. Pre-staining thin layer chromatography method for amino acid detection. African Journal of Biotechnology. 9, 8679-8681.

[4] Ramar Murugan and Gopal Rao Mallavarapu., 2013. $\alpha$-Bisabolol, the main constituent of the essential oil of Pogostemon speciosus. Industrial Crops and Products. 49, 237-239.

[5] Arie Fitzgerald Blank., Tricia Cavalcanti Pergentino Santana., Priscilla Santana Santos., Maria Fatima Arrigoni-Blank., Ana
Paula do Nascimento Prata., Hugo Cesar Ramos Jesus., Pericles Barreto Alves., 2011. Chemicalcharacterizationof the essential oil from patchouli accessions harvested over four seasons. Industrial Crops and Products. 34, 831-837.

[6] Kuntal Das, N. K., Nilesh, K., Gupta, S., Viyayabhaskar, U.M., Manjunath 2011. Anti microbial potential of pachouli oil cultivated on acidic zone of South India. India Journal of Noval drug discovery. 3, 104-111.

[7] Yu Cui Li., Shao-Zhong Peng, Ming Chen, Feng-Xue Zhang, Pei Ping Xu, Jian HuiXie., 2012. Oral administration of patchouli alcohol isolated from Pogostemon Herba augments protection against influenza viral infection in mice. International Immunopharmacology. 12, 294-301.

[8] Jin Boo Jeong., Yong Kyu Shin, Seong-Ho Lee., 2013 Antiinflammatory activity of patchouli alcohol in RAW264.7 and HT29 cells. Food and Chemical Toxicology. 55, 229-233.

[9] Ji-Yan Sua., Li-Rong Tana., Ping Lai., Hai-Chun Lianga., Zhen Qinb., Mu-Rong Yeb,Xiao-Ping., Lai Zi-Ren Su., 2012. Experimental study on anti-inflammatory activity of a TCM recipe consisting of the supercritical fluid $\mathrm{CO}_{2}$ extract of Chrysanthemum indicum, Patchouli Oil and Zedoary Turmeric Oil in vivo. Journal of Ethnopharmacology. 141, 608-614.

[10] Anon 1998. Quality Control Methods for Herbal Materials, World health Organization (WHO).

[11] Abeysinghe, D.C., Li X. Sun, C., Zhang, W., Zhou, C., Chen. K, 2007. Bioactive compounds and antioxidant capacities in different edible tissues of citrus fruits of four species. Food chemistry, 104, 1338-1344.

[12] Benzie, I.F.F., and Strain,J.J., 1996. The ferric reducing ability of plasma as a measure of Antioxidant Power: the FRAP assay. Journal of Analytical Biochemistry. 293, 70-76.

[13] Chandur, S., Shashidhar, S.B., Chandrasekar, M., Bhanumathy., Midhun, T., 2011. Phytochemical evaluation and anti-arthritic activity of root of Saussure alappa. Pharmacologia, 265-267.

[14] Sharanabasappa, G.K., Santosh,M.K., Shaila, D., Seetharam, Y.N and Sanjeevarao, I., 2007. Phytochemical Studies on Bauhinia racemosa Lam., Bauhinia purpurea Linn. and Hardwickia binate Roxb. E-Journal of Chemistry. 4, 21-31.

[15] Bharat Gami and Parabia M.H. 2010. Pharmacognostic evaluation of bark and seeds of Mimusop selengi L. International Journal of Pharmacy and Pharmaceutical Sciences, 2, 110-113.

[16] Rao, Y. and Xiang, B. (2009). Determination of Total Ash and Acid-insoluble Ash of Chinese Herbal Medicine Prunellae spica by Near Infrared Spectroscopy. Yakugaku Zasshi, 129 (7), 881886

[17] Kunle, O.F., Egharevba, H.O. and Ahmadu, P.O. (2012). Standardization of herbal medicines - A review. International Journal of Biodiversity and Conservation, 4 (3), 101-112.

[18] Mary E. Floyd., 1980. Phenolic chemotaxonomy of the genus Pelea A. Gray (Rutaceae). Pacific Science. 33, 153-156.

[19] Sandra Apers., Tania Naessens., Luc Pieters, Arnold Vlietinck., 2006. Densitometric thin-layer chromatographic determination of aescin in a herbal medicinal product containing Aesculus and Vitis dry extracts. Journal of Chromatography A.1112, 165-170.

[20] Peishan Xie., Sibao Chen., Yi-zeng Liang., Xianghong Wang, Runtao Tian., Roy Upton., 2006. Chromatographic fingerprint analysis a rational approach for quality assessment of traditional Chinese herbal medicine. Journal of Chromatography A. 1112, 171-180.

[21] Elamthuruthy, A.T., Shah, C.R., Khan, T.A., Tatke, P.A., Gabhe, S.Y., 2005. Standardization of marketed Kumariasava-an Ayurvedic Aloe vera product. Journal of Pharmaceutical and Biomedical Analysis. 37, 937-941.

[22] Abeysinghe, D.C., Wijerathne, S.M.N.K., Dharmadasa, R.M (2014). Secondary Metabolites Contents and Antioxidant Capacities of Acmella oleraceae Grown under Different Growing Systems. World Journal of Agricultural Research. 2(4), 163-167.

[23] Abeysiri, G. R. P. I., Dharmadasa, R. M. Abeysinghe, D. C. and K. Samarasinghe (2013). Screening of phytochemical, physicochemical and bioactivity of different parts of Acmella oleraceae Murr. (Asteraceae), a natural remedy for toothache. Ind. Crops Prod. 50: 852-856

[24] Dharmadasa, R.M. Samarasinghe K, Adhihetty P, and Hettiarachchi P.L. (2013) Comparative Pharmacognostic Evaluation ofMunronia Pinnata (Wall.) Theob. (Meliaceae) and Its Substitute Andrographis paniculata (Burm.f.) Wall. Ex Nees (Acanthaceae). World Journal of Agricultural Research 1, no. 5: 77-81. 
[25] Dharmadasa, R.M., Asitha Siriwardana, Kosala Samarasinghe, and Adhihetty, P. (2013). Standardization of Gyrinops Walla Gaertn. (Thymalaeaceae): Newly Discovered, Fragrant Industrial Potential, Endemic Plant from Sri Lanka. World Journal of Agricultural Research 1, No. 6: 101-103.

[26] Sundaresan, S.P. Singh and Mishra, A.N., 2009. Composition and Comparison of Essential oils of Pogostemon cablin (Blanco) Benth. (Patchouli) and Pogostemon travancoricus Bedd. var. travancoricus. Journal of Essential Oil Research. 21, 220-222.

[27] Bunrathep, S., Lockwood, G.B., Songsak, T. and Ruangrungsi. N. 2006. Chemical constituents from leaves and cell cultures of Pogostemon cablin and use of precursor feeding to improve patchouli alcohol level. J. Sci. Asia. 32, 293-296.
[28] Nguyên Xuân D ung., Piet A. Leclercq., Tran Huy Thai and La Dinh Moi., 1989. Chemical Composition of Patchouli Oil from Vietnam. J. Essent. Oil Res. 1.

[29] Abdullah Ijaz Hussain, Farooq Anwar, Tahira Iqbal., 2010. Antioxidant attributes of four Lamiaceae essential oils. Pak. J. Bot. 43, 1315-1321.

[30] Farnsworth N.R., 1966 Biological and phytochemical screening of plants. Journal of pharmaceutical Science. 55, 225-276.

[31] Benavente, G.O., Castillo, J., Marin, F.R., Ortuno, A., Del, R.J.A. (1997). Uses and properties of citrus flavonoids. Journal of Agricultural and Food Chemistry, 45(12) 4505-4515. 